\title{
A reorganização das relações de produção no campo: agronegócio e trabalho (Oeste do Paraná, final do século XX e início do século XXI) ${ }^{1}$
}

\section{The reorganization of production relations in the field: agribusiness and labor (West Paraná, late 20th century and early 21st century)}

\author{
Vagner José Moreira*
}

\begin{abstract}
Resumo
O artigo apresenta os resultados da pesquisa sobre a história e historiografia da experiência social de sujeitos vinculados à avicultura na região Oeste do Paraná, a partir da década de 1970 e início do século XXI. Com a diversificação e tecnificação das atividades agropecuárias nas pequenas propriedades, moldados pelo agronegócio a partir da década de 1990, o trabalho passou a não ser apenas familiar, ocorrendo à contratação de trabalhadores para o trabalho na produção agropecuária, o que alterou as relações de trabalho no campo.
\end{abstract}

Palavras-chave: Camponeses, Avicultores, Agronegócio, História social.

\begin{abstract}
The article introduces the results of research on the history and historiography of the social experience of diverse subjects related to the poultry industry in western Paraná, Brazil, from the 1970s and early twenty-first century. With the diversification and technification of agricultural activities on small properties, molded by agribusiness from the 1990s, the work has not only familiar, occurring to the hiring of workers to work in the agricultural production, which changed working relationships in the field.
\end{abstract}

Keywords: Peasants, Poultry farmers, Agribusiness, Social history.

\footnotetext{
${ }^{1} \mathrm{O}$ texto apresenta resultados da pesquisa de pós-doutorado em História Social do Trabalho, pela Universidade Estadual de Campinas - UNICAMP, "História da avicultura no Oeste do Paraná: trabalhadores e o processo industrial de produção de frangos (1970-2013)". E compõe parte do texto para a Promoção de Docente à Classe de Professor Associado, Universidade Estadual do Oeste do Paraná. Financiamento CNPq. "Doutor em História Social pela Universidade Federal de Uberlândia. Professor associado da Universidade Estadual do Oeste do Paraná. E-mail: vagner.jose.moreira@gmail.com
} 


\section{Introdução}

A história e a memória sobre o trabalho e a produção industrial da carne de frango no Brasil estão em disputa. A versão hegemônica construída para esse processo histórico pode ser evidenciada em diversos periódicos especializados sobre a avicultura industrial, em suplementos periódicos sobre o agronegócio, entre outros materiais. A publicação A saga da avicultura brasileira, produzida pela União Brasileira de Avicultura (UBAFEF), é representativa dessa memória hegemônica, que transformou a produção de frango do modo artesanal e familiar para avicultura industrial, ocultando a expropriação e exploração dos trabalhadores do campo e da cidade, a partir de uma narrativa laudatória, que sacraliza, edifica e mitifica a "saga e a contribuição da avicultura brasileira, revelando uma trajetória de sucesso raramente encontrada na História mundial", ${ }^{2}$ em detrimento da tragédia humana, que se constituiu história da indústria de alimentos no Brasil: o processo agudo de adoecimento dos trabalhadores. ${ }^{3}$

O processo industrial da produção de frangos consistiu na organização da cadeia produtiva de aves em um mercado oligopolizado por empresas multinacionais na área do "melhoramento genético", com a produção poedeiras avós e matrizes de pintainho de um dia para a engorda, na produção da ração industrializada a base de milho e soja, na criação de produtos veterinários diversos visando à sanidade e o controle de doenças, na industrialização de equipamentos para a instalação de aviários no campo e frigoríficos nas cidades. ${ }^{4}$ A avicultura industrial alterou o trabalho de produção do frango para o abate, que era habitualmente realizada apenas pelas próprias famílias dos

\footnotetext{
${ }^{2}$ COSTA, S. (coord.); FERREIRA, M. The saga of the Brazilian poultry: how Brazil has become the Word's largest exporter of chicken meat. A saga da avicultura brasileira: como o Brasil se tornou o maior exportador mundial de frango. Rio de Janeiro: Insight; São Paulo: UBABEF, 2011. p. 8. Disponível em: http://www.insightnet. com.br/publica/LIVRO_A\%20saga\%20do\%20frango_site.pdf. Acesso em: 28 fev. 2013.

${ }^{3}$ Cf. VARUSSA, R. J. (org.). Eu trabalhava com dor: trabalho e adoecimento nos frigoríficos. Jundiaí: Paco Editorial, 2016.

${ }^{4}$ A União Brasileira de Avicultura (UBABEF) produziu sua versão para avicultura industrial: "No mundo todo, para que a indústria progredisse, técnicos e cientistas se movimentaram para produzir aves mais econômicas e produtivas, rações mais eficientes e mais adequadas, manejo mais simples e mais perfeito, mão de obra mecanizada e menos onerosa, sistemas de criação mais compatíveis e mais higiênicos, medicamentos preventivos e especializados para ativar o desenvolvimento das aves, meios práticos de embalagem e conservação dos produtos etc." COSTA (coord.); FERREIRA, op. cit. p. 33. A UBAFEF deixou de existir em 2014 com a criação da ABPA, com Francisco Turra ainda como presidente executivo: "Empresas e entidades das cadeias agroindustrias de aves, ovos e suínos de todo o Brasil reuniram-se no dia 24 de março de 2014 para criar a Associação Brasileira de Proteína Animal (ABPA), que nasceu a partir da junção da União Brasileira de Avicultura (UBAFEF) e da Associação Brasileira da Indústria Produtora e Exportadora de Carne Suína (ABIPECS). Disponível em: http://abpa-br.com.br/institucional. Acesso em 8 set. 2017.
} 
pequenos proprietários rurais integradas às fábricas processadoras de carne de frango, por exemplo, no Oeste do Paraná, as empresas C. Vale - Cooperativa Agroindustrial, Cooperativa Agroindustrial Copagril, Coopavel - Cooperativa Agroindustrial de Cascavel, Cooperativa Agroindustrial Lar, Globoaves e Sadia - atual BR Foods -, entre outras, utilizando-se de trabalhadores rurais contratados para a atividade. ${ }^{5}$

A partir da década de 1970 e o início do século XXI, as dinâmicas do trabalho rural e as relações de trabalho no campo foram transformadas com a diversificação e tecnificação das atividades agropecuárias nas pequenas propriedades. $O$ trabalho rural deixou de ser apenas familiar, pois a produção agropecuária congregou o trabalho em aviários, a ordenha de vacas para a produção de leite, o trabalho em granja de suínos e todas as atividades inerentes à produção agrícola mecanizada de soja e milho, entre outras atividades. ${ }^{6}$ Pelo menos, desde o início da década de 1990, o discurso ideológico do agronegócio para a viabilidade econômica da agropecuária passou a orientar a gestão não apenas das grandes e médias propriedades, mas também de parte significativa dos pequenos proprietários. ${ }^{7}$ Na região Oeste do Paraná, a forte presença de empresas e cooperativas agroindustriais há mais cinco décadas articula e molda econômica e politicamente a organização da produção agropecuária.

\footnotetext{
${ }^{5}$ Os frigoríficos são denominados pelos trabalhadores como fábricas de "moer gente". A expressão é comum entre os trabalhadores e utilizada para expressar a ironia do trabalho humano em fábricas de processamento de carne de aves, suínos e bovinos. No sítio eletrônico "Moendo gente" é possível ter acesso a diversas reportagens produzidas pela a ONG Repórter Brasil sobre o trabalho em frigoríficos. Disponível em: www.moendogente.org.br. Acesso em 13 jun. 2014.

${ }^{6}$ É comum a literatura especializada afirmar que a cadeia produtiva do frango criou um mercado a "jusante e a montante da porteira da fazenda". A produção acadêmica sobre a organização da produção da cadeia produtiva do frango é vasta, entre outros, Cf. SILVA, R. N. B. Trabalho integrado e reprodução do capital: um estudo de caso no Sudoeste do Paraná. 2011. 414 f. Tese (Doutorado em História Social) - Programa de Pós-Graduação em História Social da Universidade Federal Fluminense, UFF, Niterói, 2011. SORJ, B; POMPERMAYER, M. J.; CORADINI, O. L. Camponeses e agroindústria: transformação social e representação na avicultura brasileira. Rio de Janeiro: Biblioteca Virtual de Ciências Humanas do Centro Edelstein de Pesquisas Sociais, 2008. Disponível em: http://www.bvce.org.br/LivrosBrasileirosDetalhes.asp?IdRegistro=37. Acesso em: 14 abri. 2010. DALLA COSTA, A. J. Agroindústria brasileira contemporânea: inovações organizacionais e transformações tecnológicas na avicultura. 1997. 352 f. Tese (Doutorado - Autos Estudos em América Latina) - IHEAL, Université De La Sorbonne Nouvelle, Paris III. 1997.

${ }^{7}$ Sobre o agronegócio, Cf. MENDONÇA, S. R. "Estado e hegemonia do agronegócio no Brasil". História \& Perspectivas, Uberlândia, n. 32/33, p. 91-132, jan.jul/ago. dez. 2005. HEREDIA, B.; LEITE, S. P.; PALMEIRA, M. “Sociedade e economia do 'agronegócio' no Brasil". Revista Brasileira de Ciências Sociais, v. 25, n. 74, p. 159-196, out. 2010.
} 


\section{A unidade familiar no campo e a integração da produção avícola}

A produção agropecuária na região Oeste do Estado do Paraná é significativamente apresentada no conjunto da produção nacional, destacando-se a produção de leite, de suínos e de galináceos. ${ }^{8}$ E na produção de frango o Paraná se destaca como o principal produtor" "tornando-se líder nacional no seguimento avícola", conforme a jornalista Luana Gomes, da Gazeta do Povo, organizadora da "Expedição Avícola" no Paraná, que se constituiu numa série de reportagens do periódico sobre a cadeia avícola:

O presidente do Sindicato das Indústrias de Produtos Avícolas do Estado do Paraná (Sindiavipar), Domingos Martins, atribui o avanço paranaense a uma série de fatores, como o crescimento do número de avicultores e de abatedouros, quase todos habilitados à exportação, e à disponibilidade de matéria-prima. "O Paraná é privilegiado. Somos os maiores produtores de grãos do país e, tendo soja e milho à vontade como nós temos aqui, é mais fácil fazer frango", observa. Hoje, o Paraná tem mais de 18 mil avicultores integrados a 42 indústrias, entre abatedouros e incubatórios. Essas empresas são as responsáveis pela produção anual de mais de um bilhão de cabeças de frango - quase 4 milhões de aves por dia. As 28 indústrias paranaenses habilitadas para exportação vendem todos os anos mais de 1 bilhão de toneladas de carne de frango para 130 países dos cinco continentes, injetando na economia do estado mais de US\$ 2 bilhões.

Todo o frango produzido no Paraná vem das granjas de matrizes espalhadas pelo estado.

Além de gerar receita, essas indústrias também têm um papel muito importante na distribuição da renda. "Não existe outro setor dentro do agronegócio que empregue tanto quanto a avicultura", sustenta Martins. De acordo com o Sindiavipar, a cadeia avícola paranaense gera atualmente 50 mil postos de trabalho diretos e 500 mil empregos indiretos..$^{10}$

Para os sujeitos implicados com a avicultura industrial é comum a expressão "fazer frango" assumir o sentido literal de industrialização - fabricação - do frango. Com a expressão desaparece o sentido natural e artesanal do processo de nascimento, criação e engorda do frango, anteriormente relacionado a produção de galinhas caipiras. A expressão também é comum aos avicultores e trabalhadores de aviários no campo, que estão diretamente

\footnotetext{
${ }^{8}$ INSTITUTO BRASILEIRO DE GEOGRAFIA E ESTATÍSTICA - IBGE. Produção da Pecuária Municipal 2007. Rio de Janeiro, 2008.

${ }^{9}$ AVICULTURA INDUSTRIAL. Abate de frangos e suínos registram alta no Brasil, diz IBGE. Disponível em: http://www.aviculturaindustrial.com.br/noticia/abate-de-frangos-e-suinos-registram-alta-no-brasil-diz-ibge/20130920083915_S_846. Acesso em 25 set. 2013.

${ }^{10}$ GOMES, L. Frango do Paraná dá nova "revoada". Gazeta do Povo, Expedição Avicultura. Agronegócio. 24/07/2012. Disponível em: https://www.gazetadopovo.com.br/agronegocio/agricultura/frango-do-parana-da-nova-revoada-cee3usxfa3cgj690k7wit9aql/. Acesso em: 25 jul. 2012. (Grifo nosso).
} 
em contato com as aves no processo de engorda do frango, quando recebem o pintainho de um dia das indústrias por meio de contratos de integração.

O número significativo de trabalhadores rurais envolvidos na produção de aves no campo e de trabalhadores urbanos nas indústrias de processamento de carne é relevante na região Oeste do Paraná. O aumento do consumo da produção agropecuária, em particular da carne, do leite e da soja, também é enfatizado pela série de reportagens da "Expedição Avícola", suplemento Agronegócio, do periódico Gazeta do Povo. Contudo, sem dimensionar a exploração e os impactos sobre os trabalhadores vinculados a essas cadeias produtivas, que a cada dia amplia os índices de adoecimento e mutilação. ${ }^{11}$

A história da indústria da alimentação no Oeste do Paraná está vinculada a criação dos processos de agroindustrialização de diversas cadeias produtivas agropecuárias. As atividades agroindustriais foram diversificadas e incluem indústrias para o processamento de soja, milho, trigo, leite e carnes de aves, suínos, peixes, entre outras. De fato, a imagem de autossuficiência dos portfólios das indústrias de alimentação do Oeste do Paraná, que abastecem as gôndolas dos supermercados em todo o Brasil, corrobora as narrativas sobre a pujança do "desenvolvimento regional" e espreita ocultar a intensa exploração dos trabalhadores. Por outro lado, a realidade vivida pelos trabalhadores da cadeia avícola evidencia o extremo das contradições da agroindustrialização. ${ }^{12}$

A família Enge tem uma pequena propriedade em Bom Jardim, bairro rural do município de Marechal Cândido Rondon. A família é composta pelo pai, mãe e duas irmãs: “aqui o clã é controlado pela mulherada!”, exclamou

\footnotetext{
${ }^{11}$ Cf. BOSI, A. P. "Um ensaio sobre industrialização, desenvolvimento econômico e trabalho degradado no Oeste do Paraná". In: BOSI, A. P. Precarização e intensificação do trabalho no Brasil recente: ensaios sobre o mundo dos trabalhadores (1980-2000). Cascavel: Edunioeste, 2011. BOSI, A. P. "História das relações de trabalho na cadeia produtiva avícola no Brasil (1970-2010)”. Revista de História Regional, v. 16, n. 2, p. 400-430, 2011. BOSI, A. P. "A recusa do trabalho em frigoríficos no Oeste paranaense (1990-2010): a cultura da classe". Diálogos, Maringá, online, v. 17, n. 1, p. 309-335, jan. abr./2013. HECK, F. M. No abate de frangos e suínos: o descarte do trabalho. Curitiba: Editora Prismas, 2017. HECK, F. M. O espaço e o contraespaço no circuito produtivo da frigorificação de carnes no Oeste Paranaense. 2017. 348f. Tese (Doutorado em Geografia) - Programa de PósGraduação em Geografia, Universidade Estadual Paulista Julio de Mesquita Filho, Presidente Prudente. VARUSSA, R. J. “Trabalhadores e frigoríficos na Justiça do Trabalho: Oeste do Paraná, décadas de 1990 e 2000". In: GOMES, A. C; SILVA, F. T. A Justiça do Trabalho e sua história: os direitos dos trabalhadores no Brasil. Campinas: Editora da Unicamp, 2013.

${ }^{12} \mathrm{Cf}$. MOREIRA, V. J. “Agronegócio, trabalhadores rurais, sindicalismo: avicultura no Oeste do Paraná, 1970-2013". In. História e Perspectivas, Uberlândia, vol. 55, p. 243-270, jul./dez. 2016. Disponível em: http:// www.seer.ufu.br/index.php/historiaperspectivas/article/view/35786/18916. Acesso em: 29 ago. 2019. MOREIRA, V.J. "O trabalho em matrizeiro de aves e o adoecimento dos trabalhadores da cadeia produtiva do frango". In. VARUSSA, R. J. (org.) Eu trabalhava com dor: trabalho e adoecimento nos frigoríficos. Jundiaí: Paco Editorial, 2016.
} 
Valmi Enge. ${ }^{13}$ A entrevista foi realizada com Valmi e Noemi Enge. As atividades agropecuárias na pequena propriedade foram diversificadas com a produção de frango, leite, soja e milho. As irmãs fizeram o curso superior de Biologia, mas sem concluir com a entrega do TCC, pois receberam a proposta dos pais para assumirem o trabalho com os aviários que projetavam construir. A decisão não foi difícil para as duas, pois, "não viam futuro como professoras", tal como relatado.

A família terminou a construção do quarto galpão para a engorda de frango em meados do ano de 2013, mas iniciaram na atividade logo que a Copagril Cooperativa Agroindustrial começou com a produção de frango em 2005. A integração com a cooperativa foi mantida até 2011 e depois se integraram a uma agroindústria de Itaquiraí, Mato Grosso do Sul. Para o rompimento do contrato de integração com a cooperativa as irmãs Enge avaliaram que as exigências para o manejo e a organização do trabalho não compensavam os resultados. Além da pressão para a comercialização de toda a produção e consumo transcorresse nas lojas agropecuárias e supermercados da cooperativa. As irmãs Enge também consideravam vexatório o tratamento que recebiam dos técnicos da cooperativa, que desconsideravam o conhecimento e a experiência do trabalho diário. ${ }^{14} \mathrm{Na}$ propriedade possuem quatro galpões com capacidade média de 23 mil frangos cada um, mas estão alojando apenas 21 mil em cada galpão, pois, na avaliação dos técnicos, é melhor para o manejo das aves e para os resultados com a engorda dos frangos.

O trabalho familiar foi dividido na pequena propriedade: Noemi é responsável pelos aviários, a mãe e a Valmi responsáveis pela produção do leite e o pai da produção da soja e do milho. A família contratou permanentemente um trabalhador assalariado para "colaborar" com o trabalho em todas as

\footnotetext{
${ }^{13} \mathrm{O}$ universo de evidências para pesquisa foram compostas por 57 entrevistas produzidas pelo autor e bolsistas de iniciação científica com trabalhadores rurais e proprietários rurais. Os pseudônimos foram utilizados apenas quando solicitados pelos entrevistados e indicados entres parênteses nas referências. Cf. MOREIRA, V.J. Propriedades da evidência, narrativas orais e a escrita da história: memórias sobre trabalhadores na luta pela terra. História e Perspectivas, Uberlândia, n. 48, p. 239-282, jan./jun. 2013. Disponível em: http://www.seer.ufu.br/index.php/historiaperspectivas/article/view/23308/12843. Acesso em: 29 ago. 2019. MOREIRA, V. J. Agronegócio e a avicultura no Deste do Paraná. Trabalhadores e o processo industrial de produção de frangos (1970-2013). 2017. Promoção à Classe de Professor Associado, Universidade Estadual do Oeste do Paraná, 2017.

${ }^{14}$ É comum entre os avicultores os relatos que denunciam a intransigência e autoritarismo das áreas de fomento das agroindústrias para com os avicultores, impondo o saber técnico em detrimento do saber aprendido no trabalho diário com a engorda dos frangos. O problema ocorre tanto com relação as cooperativas agroindustriais quanto em empresas como a BR Foods. Sobre a relação tensa entre avicultores e técnicos das agroindústrias, Cf. TOEBE ZEN, R. O processo de trabalho dos avicultores parceiros da Sadia S.A.: controles, mediações e autonomia. 2009. 124 f. Dissertação (Mestrado em Educação) - Programa de PósGraduação em Educação, Universidade Estadual do Oeste do Paraná, 2009.
} 
atividades agropecuárias. Para a realização do trabalho nos aviários Valmi conta com a força de trabalho do trabalhador contratado nas duas primeiras semanas para o manejo dos pintainhos, o período que exige mais trabalho, e na preparação dos aviários para receber o lote seguinte de pintainhos de um dia, que consiste na higienização dos galpões e remexer ou trocar a cama de maravalha dos aviários.
Valmi: [...] os colonos não é mais assim que nem era. "Ah, tem umas vaquinhas lá pode pegar água de rua, de cidade, água clorada de rua encanada pra beber, não de poço." "Pode tá". Aí um belo dia chega lá pergunta: "Quantas vaquinhas você tem?" "Ah, eu tenho 70 vaquinhas." Entende? Porque hoje em dia não sobrevive com pouco. Não adianta você querer ficar com 15 vacas. Ou menos, aqui com um aviário. Vai colocar hoje em dia um aviário, não compensa. Não coloca um aviário. Um aviário, um aviário vai para pagar a despesa dos outros três. Se dá o suficiente para pagar a luz, pra pagar a maravalha, pra pagar o resto que vai, entendeu? E pagar daí se tiver no caso um funcionário, aí piora a situação mais ainda. Porque tem que paga o funcionário, paga o FGTS, todos estes encargos que tem em cima. Não adianta mais querer ser pequeno hoje em dia. Não dá mais, aí aumenta tudo. [...] Hoje em dia eu falo: "quem está só com lavoura é meio louco”, eu acho. É muito arriscado esse negócio de lavoura. Quando dá, dá muito bem. Este lado eu entendo, te sobra dinheiro, que nem agora deu esse ano muito bem. $O$ frango sempre te dá aquilo, que nem o leite. O leite também sempre te dá aquilo, mas é uma certeza que tu tens que vai entrar. [...]
Noemi: Por isso tu tem que ter muito. Pra te sobrar mais. Quanto mais a despesa é mais alta, mas também o que sobra mais alto. É o único jeito. Cada vez você tem que ter mais pra sobrar mais. ${ }^{15}$

O trecho do relato foi construído para dimensionar as dificuldades que passaram com a COPEL, empresa fornecedora de energia elétrica no Estado do Paraná, na construção de mais um aviário, pois a empresa exigiu a instalação elétrica trifásica, que elevou os custos da construção do novo aviário.

Na região é comum aos proprietários rurais a sua identificação como “colonos". A designação refere-se aos proprietários rurais que se deslocaram para a região Oeste do Paraná a partir da década de 1950 e compraram suas propriedades das empresas "colonizadoras". Os "colonos" foram construídos pela memória e história locais como "pioneiros" que "desbravaram" as florestas e forjaram o "desenvolvimento regional". As narrativas míticas e laudatórias expressam a ocultação histórica dos diversos sujeitos que habitavam a região no período anterior a 1950. O ocultamento histórico também

\footnotetext{
${ }^{15}$ ENGE, Valmi; ENGE, Noemi. Entrevista realizada pelo autor e Salete Inês Walter em 9 mar. 2013. Duração: $1 \mathrm{~h} 48 \mathrm{~min}$. (Grifo nosso).
} 
dos trabalhadores rurais sem terra no trabalho de formação das propriedades, que incluía o desmatamento e o plantio na área por um a três anos como arrendatários e parceiros, assim como o silêncio sobre os movimentos sociais por direitos trabalhistas e na luta pela terra. ${ }^{16}$

Para as irmãs Enge, a produção industrial de frango está em contínua "mutação" - "ou você muda ou você para" - e concluíram que não é possível sobreviver no campo sendo um pequeno produtor. As exigências com o manejo do frango, aviários com capacidade cada vez maior, instalação de equipamentos para a automação do trabalho, equipamentos para o controle da temperatura (exaustor, nebulizador, aquecedor) para a climatização ideal considerando a idade do frango e a estação do ano -, entre outras tecnologias, são introduzidas ano a ano na avicultora. Contudo, a avicultura industrial para os pequenos proprietários tem-se apresentado viável economicamente. Os avicultores Pedro Timbola e Leomar Casarolli celebraram o aumento no valor pago por cada frango. Para um produtor que possui quatro aviários com capacidade média para vinte mil aves alojadas em cada um, saltou de $\mathrm{R} \$ 0,60$ por animal no ano de 2013, para $\mathrm{R} \$ 0,65$ e $\mathrm{R} \$ 0,70$ por animal no ano de 2014 . O setor calcula que o custo médio para o avicultor na produção avícola esteja em torno de 50\%; essa estimativa desconsidera os valores daqueles avicultores que pagam semestralmente as parcelas do financiamento para a construção dos galpões. Para a cooperativa de Cascavel, a Copavel, a estimativa foi de aumento de $10 \%$ na produção para o ano de $2014 .{ }^{17}$

A produção de frangos pelos avicultores constitui em uma etapa da cadeia produtiva agroindustrial de aves:

A cadeia produtiva da avicultura de corte apresenta uma trajetória das mais interessantes dentre as cadeias produtivas agroindustriais no Brasil, marcada por constantes evoluções técnicas, um adensamento constante e estreitas colaborações entre seus integrantes que resultaram na conquista do mercado interno, gradativamente suplantando concorrentes na oferta de proteína animal ou no mercado externo, superando os principais fornecedores avícolas mundiais.

\footnotetext{
${ }^{16}$ Cf. CUNICO, J. M. Viver e trabalhar no campo: produção agropecuária, relações de trabalho e tensões no Extremo Oeste paranaense, 1970-2012. 2014. 136 f. Dissertação (Mestrado em História) - Programa de Pós-graduação em História, Universidade Estadual do Oeste do Paraná, Marechal Cândido Rondon, 2014. VARUSSA, R. J. "Pioneiros da flexibilização e os boias-frias da indústria: Oeste do Paraná, década de 1980." In: BOSI, A. (org.) Trabalho e trabalhadores no processo de industrialização recente no Oeste do Paraná (1970-2010): estudos sobre a cadeia avícola. Jundiaí: Paco Editorial, 2014.

${ }^{17}$ GLOBO RURAL. Produtores de frango comemoram o bom momento da atividade no PR. Disponível em: http://g1.globo.com/economia/agronegocios/noticia/2013/12/produtores-de-frango-comemoram-o-bom-momento-da-atividade-no-pr.html. Acesso em: 4 jun. 2014.
} 
Da adaptação da tecnologia de integração de aviários por abatedouros industriais, passando pela importação de pintos avós por via aérea (que foi capa da primeira revista Manchete Rural em 1987) para chegar aos aviários totalmente automatizados dos dias de hoje passaram-se cerca de 40 anos. ${ }^{18}$

Na região Oeste do Paraná, a produção organizada por cooperativas agroindustriais ou empresas, tais como, a BRF Foods e Globoaves, com o sistema de integração da produção, data a década de 1970. Em 1976 a Sadia iniciou com a integração de suinocultores e, posteriormente, em 1979, com a integração de avicultores. Contudo, a integração agroindustrial foi utilizada pela Sadia no início da década de 1960, em Santa Catarina, importando o modelo dos Estados Unidos. Em Toledo, no início da integração para a produção de frangos pela Sadia, 90\% dos avicultores também eram suinocultores integrados. Naquele momento, a Sadia privilegiava a integração de produtores de um a três aviários. ${ }^{19}$ Um contraste com os aviários Dark House ${ }^{20}$ e avicultores com até onze galpões construídos em suas propriedades no presente. ${ }^{21}$

O deslocamento da matéria-prima para o processamento nas indústrias é realizado pelos caminhões que transportam os frangos até o abatedouro. Anteriormente, a mão de obra para o carregamento dos caminhões era de responsabilidade dos avicultores, que com a sua família ou com a contratação de terceiros, realizavam o transporte dos frangos dos aviários até os caminhões. Como é o caso da família Adams:

Isolde: A Sadia traz o pintinho, entrega a ração e faz toda a assistência veterinária. Nós entramos só com o serviço. Inclusive os carregadores dos frangos é a Sadia que manda as equipes de Toledo. [...] Antigamente era por nossa conta. E depois eles [Sadia] viram que começou. Porque quando a gente

\footnotetext{
${ }^{18}$ JESUS JUNIOR, C. at al. "A cadeia da carne de frango: tensões, desafios e oportunidades". In: BNDES Setorial. Agroindústria. Rio de Janeiro, n. 26, p. 191-232, set. 2007. Disponível em: http://www.bndes.gov. $\mathrm{br} /$ SiteBNDES/export/sites/default/bndes_pt/Galerias/Arquivos/conhecimento/bnset/set2607.pdf . Acesso em: 24 ago. 2011.

${ }^{19}$ RIBEIRO, I. O.; CESAR, P. B.; BESNOSIK, R. I. Modernização e diferenciação social na agricultura brasileira: um estudo no Extremo-Oeste do Paraná. Relatório Final Extremo-Oeste Paranaense. Projeto de evolução recente e situação atual da agricultura brasileira. Rio de Janeiro: Ministério da Agricultura/Fundação Getúlio Vargas, 1981. p. 117.

${ }^{20} \mathrm{O}$ sistema Dark House foi implementado na avicultura industrial nos Estados Unidos e na Europa. A sua implantação no Brasil ocorreu diante das pressões por aumento da produtividade. "O sistema Dark House, quando aplicado na criação de frangos, condiz na construção de aviários totalmente fechados, com ventilação artificial tipo túnel e luz artificial, objetivando controlar todas as variáveis ambientais dentro do galpão, inclusive a iluminação." AVICULTURA INDUSTRIAL. Workshop sobre Dark House na avicultura chega a um modelo ideal do sistema para o Brasil. Disponível em: https://www.aviculturaindustrial.com. br/imprensa/workshop-sobre-dark-house-na-avicultura-chega-a-um-modelo-ideal-do-sistema-para-o-brasil/20130516-075232-u527. Acesso em 17 mai. 2013.
}

${ }^{21}$ BERNARTT, Luiz Ari. Entrevista realizada pelo autor em 24 fev. 2014. Duração: 60 min. 
pegava as pessoas, fazia mutirão de pessoas, umas pegava pelas asas, outras pelas patas. E o frango chegava lá machucado. E agora não eles têm todo o cuidado pra fica melhor agora. Porque tem a questão de arranhadura, a gente perde o percentual se tem arranhadura. E com esta equipe não tem mais a questão de arranhaduras. [...] A gente pagava o dia. E além do dia dava o almoço, a janta, ou fazia lanche. E também tem a questão de se machucar no aviário. Porque pode que a pessoa se machuca e se for um vizinho a gente tem que dá assistência, e assim não, é a equipe de lá é responsável. Eles veem e carregam. ${ }^{22}$

A senhora Isolde e senhor Ari possuem um aviário na pequena propriedade em Marechal Cândido Rondon há mais de duas décadas. A propriedade foi adquirida de um tio, que tinha o aviário construído na propriedade há quase 20 anos. Certamente, um dos primeiros aviários em Marechal Cândido Rondon, construído no final da década de 1970. A família Adams possuía uma propriedade maior, mas por problemas de saúde de uma filha avaliaram que era melhor vender essa propriedade e comprar uma menor para custear o tratamento de saúde. E, assim, iniciaram com a avicultura. Além dos frangos também engordam suínos, com integração com a Sadia, e engordam gado bovino. Mesmo com a inauguração do frigorífico da Copagril Cooperativa Agroindustrial em 2005 mantiveram o contrato de integração com a Sadia, pois avaliaram naquele momento que seria melhor. $\mathrm{O}$ antigo aviário passou por reformas e atualização tecnológica, adaptado para as exigências da Sadia. No aviário já produziram o frango grill, que leva 28 dias para a engorda.

O relato da senhora Isolde é significativo para evidenciar as transformações da organização do trabalho no campo. A intensificação do uso de tecnologias para a produção agropecuária - a alteração na base técnica - gerou um excedente de mão de obra entre as famílias de pequenos proprietários rurais e de trabalhadores rurais não proprietários que habitavam o campo. A mão de obra excedente desses sujeitos era utilizada para a "apanha" dos frangos no aviário e no carregamento do caminhão para o transporte até a indústria.

Na narrativa aparece o termo "mutirão", que foi consagrado pela literatura para expressar as relações de solidariedade e vizinhança na realização do trabalho rural. ${ }^{23} \mathrm{O}$ mutirão era uma prática social utilizada pelas unidades

\footnotetext{
${ }^{22}$ ADAMS, Isolde. Entrevista realizada por Salete Inês Walter, em 25 de maio de 2013. Duração: 33 min.

${ }^{23} \mathrm{O}$ mutirão de trabalho - mutualismo de trabalho - constitui-se como prática social entre os pequenos proprietários rurais e trabalhadores rurais até pouco tempo no campo, hoje a prática é pouco usual na região Oeste do Paraná, que passou pela reorganização das relações de produção no campo. "O mutualismo de trabalho frequentemente perde importância quando a economia local passa a girar em torno do dinheiro. Aumenta então a tendência a comprar com dinheiro a execução de tarefas específicas." LINDEN, M. van der. Trabalhadores do mundo: ensaios para uma história global do trabalho. Campinas: Editora da Unicamp, 2013. p. 97.
} 
familiares para a realização do trabalho no campo nos momentos que a mão de obra familiar não era suficiente, nos períodos de plantação, limpeza da roça e colheita. Contudo, o mesmo termo foi apropriado pela narradora para designar outra relação social, pois os vizinhos eram chamados para o trabalho, mas o dia de trabalho era remunerado. ${ }^{24}$ Por outro lado, a narrativa expressa também a preocupação da avicultora com as responsabilidades legais para com os trabalhadores contratados como diaristas; é um vizinho, moralmente, deveriam assumir os custos com médicos, remédios e os dias parados para o caso de acidente ou adoecimento no trabalho. Como sugere Alessandro Portelli, quando um evento é narrado como possibilidade, certamente o fato ocorreu com o sujeito ou outrem, considerado verossímil e, assim, informa os referenciais compartilhados socialmente pelos sujeitos. ${ }^{25}$

Para o senhor Luiz Ari Bernartt, 65 anos quando entrevistado, presidente da Associação dos Avicultores do Oeste do Paraná (AAVIOPAR), desde seu início em 2007, organizada para defender os interesses dos avicultores junto aos frigoríficos da região, a pressão dos avicultores, por meio da AAVIOPAR, levou as agroindústrias assumir os custos desse trabalho:

Luiz Ari Bernartt: A nossa associação [AAVIOPAR] é diferente porque, nós prestamos um trabalho além de tá diretamente representado o produtor na empresa, nos bancos, nós temos a nossa atividade é nós junto com os deputados federais e prefeito. Nós conseguimos máquinas a fundo perdido. Essas máquinas fazem a limpeza de aviário, então nós temos, temos três Bobcat, vamos ter mais uma agora, a quarta Bobcat, é tudo a fundo perdido, verbas federais que saíram. Temos alguns caminhões, espalhadeira de cama de aviário, que nós estamos distribuindo entre os associados para que eles possam utilizar. E com isso a gente buscou fazer o que, não só pensar em termo de aquilo que é, é bater direto com a empresa, mas sim redução de custo de produção para o produtor. Essa redução de custo daí aconteceu o seguinte: quando nós iniciamos, um metro cúbico de maravalha chegou a estar o preço de quarenta e dois, quarenta e três reais, na época, em dois mil e sete [...]. Nós mesmos pagamos quarenta e dois reais o metro, hoje, depois de fundada, ela veio até trinta e quatro reais, porque nós estabelecemos um custo de produção e como nós adquirimos a maravalha, sem interesse em obter lucro e o preço que vem da Argentina ou vem dos fornecedores a gente repassa direto para o produtor. Então, todos os

\footnotetext{
${ }^{24}$ Uma evidência da historicidade dos conceitos, como afirma Marc Bloch, "Pois, para grande desespero dos historiadores, os homens não têm o hábito, a cada vez que mudam de costumes, de mudar de vocabulário." BLOCH, M. Apologia da história, ou, o ofício de historiador. Rio de Janeiro: Jorge Zahar Ed., 2001. p. 59. Ainda sobre a historicidade dos conceitos, Cf. WILLIAMS, R. Marxismo e literatura. Rio de Janeiro: Zahar Editores, 1979. p. 17.

${ }^{25}$ Cf. PORTELLI, A. "A filosofia e os fatos. Narração, interpretação e significado nas memórias e nas fontes orais". Tempo, Rio de Janeiro: vol. 1, no . 2, p. 59-72, 1996. PORTELLI, A. “O que faz a história oral diferente”. Projeto História, São Paulo, Educ, n. 14, p. 25-39, fev.1997.
} 
demais fornecedores tiveram que baixar esse preço se quisesse vender. Então, a maravalha baixou, baixou o custo também de empresa de aviário através dessa máquina. Nós não temos que pagar investimento de máquina, nós adquirimos uns caminhões aí, ganhamos um da prefeitura de [Nova] Santa Rosa, e temos outro que nós compramos. E com isso, esse trabalho prestado junto aos avicultores baixou o custo de produção do avicultor. Então, nós entendemos que a associação trabalha em cima de renda, diretamente com as empresas, buscando melhor remuneração, e melhor atendimento, claro. E redução de custo através de trabalho que a associação presta no fornecimento de insumos. Foi o caso da maravalha, foi o caso da limpeza de aviário. E como o nosso caso aqui na BRF, quando a BRF começou a exigir que todos fizessem fermentação dos lotes, então teria que cada um comprar lonas pra colocar nos seus aviários, a lona do aviário na época tava em setenta e cinco reais o metro, aí nós fizemos uma licitação aqui pra associação, compramos tudo em torno de cinquenta. Então, a própria empresa passou, não, o cara comprava da própria BRF e pagava setenta, setenta e um, né? Veio aqui pra associação cinquenta, então uma diferença incrível, é, as empresas que vendem, quando é uma empresa forte demais eles não olham muito, agora quando é licitação, e nós tínhamos um volume enorme de lona, se cada um adquiri, um aviário de cem metros ele dá mil e duzentos metros pra forra de lona, então mil e duzentos, cinquenta, cem, seiscentos reais dá aí pra o produtor, mais vinte reais por metro dá um valor considerável. Então, todo esse tipo de trabalho foi o que a gente brigou, de cara foi uma vantagem especial que deu pra o produtor. Sem considerar que eu acho que um dos maiores ganhos que nós tivemos no início, foi quando nós fundamos a associação e nós estávamos pagando tudo, o carregador principalmente. Além do custo do carregamento nós tínhamos o risco, se um dos carregadores tivesse um acidente na propriedade a responsabilidade trabalhista daquele acidente seria do produtor. Então, se chega a acontecer um acidente de um carregador se acidentar lá, talvez o produtor, nem os aviários dele não chegaria pra pagar toda a despesa. ${ }^{26}$

As agroindústrias assumiram os custos do carregamento dos frangos nos aviários, contudo, terceirizam para empresas que atuam vinculadas a cada agroindústria. A mão de obra desses trabalhadores na "apanha" dos frangos é caracterizada pela intensa exploração, pois além de se deslocarem para longe de suas residências, o trabalho realizado exige muita força física, é repetitivo e os trabalhadores estão destituídos de inúmeros direitos trabalhistas, tais como, carteira de trabalho assinada, seguro desemprego, entre outros. No caso de Marechal Cândido Rondon, aproximadamente 65 trabalhadores pegadores de frango e batedores de caixa trabalham para uma empresa terceirizada ao frigorífico da Cooperativa Agroindustrial Copagril. Os trabalhadores foram

${ }^{26}$ BERNARTT, Luiz Ari. Entrevista realizada pelo autor em 24 fev. 2014. Duração: 60 min. 
divididos em cinco equipes, cada equipe com oito pegadores de frango, quatro batedores de caixa e um que exerce a função de motorista e chefe da equipe. ${ }^{27}$ 0 trabalho dos pegadores de frango e batedores de caixa, nomeados pejorativamente como "graxains", constituiu-se numa atividade fundamental para o processo de agroindustrialização de aves e na manutenção da cadeia produtiva do frango - sem essa atividade os frigoríficos de aves teriam sua produção parada por falta de abastecimento da matéria-prima ou ainda sujeitos aos problemas descritos por Isolde e Luiz. As centenas de aviários integrados às fábricas foram e estão organizadas de tal modo que fornecem a matéria-prima para o processamento no tempo determinado pela gestão racionalizada da área de fomento e administração, ao ponto de não faltar às centenas de milhares de frangos para serem abatidos diariamente em cada planta frigorífica. De acordo com o planejamento, o término do período de engorda para cada lote está em sincronia diária com a demanda para a entrada da matéria-prima no abatedouro. Os relatos colhidos junto a esses trabalhadores pegadores de frango e batedores de caixa informam que, não é raro, trabalham 24 horas seguidas. Além disso, remunerados por produção - ganham por aviários.

O jovem trabalhador Roberto de Lima Martins, 19 anos de idade na data da produção entrevista, trabalhava há três anos para a empresa terceirizada. ${ }^{28}$ Roberto tem mais três irmãos que trabalhavam para a mesma empresa terceirizada. Afirma que o trabalho é pesado, com movimentos repetitivos, jornada de trabalho indefinidas, iniciando sempre à noite, pois é o momento em que as aves apresentam menos trabalho para o transporte. $O$ trabalho consiste em pegar o frango e colocá-los na caixa, para o transporte até o caminhão, num movimento contínuo de abaixar, curvar e ficar ereto. ${ }^{29}$ Roberto avalia que é melhor o trabalho como batedor de caixa e pegador de frango do que

\footnotetext{
${ }^{27} \mathrm{Cf}$. WALTER, S. I. Experiências sociais e relações de trabalho dos trabalhadores pegadores de frango e batedores de caixa de Marechal Cândido Rondon-PR. 2013. 70 f. Trabalho de Conclusão de Curso (Graduação em História) Colegiado do Curso de História, Universidade Estadual do Oeste do Paraná, Unioeste, 2013.

${ }^{28}$ MARTINS, Roberto de Lima. Entrevista realizada pelo autor e Salete Inês Walter em 8 out. 2011. Duração: 35 min.

${ }^{29}$ Numa equipe composta por oito pegadores de frango e quatro batedores de caixa no trabalho em uma propriedade com quatro aviários, com média de 20 mil frangos cada aviário. Os oito pegadores de frango são responsáveis por pegar 10 mil frangos cada um. Se em cada uma das mãos pegam dois frangos, realizam o movimento nada ergométrico e em ritmo intenso para a "apanha" do frango ao abaixar-se e levantar-se o corpo 2.500 vezes, com um peso de 10 a 12 quilos, em média, uma vez que cada frango pode pesar de 2,5 a 3 quilos cada um. Em cada caixa são alojados oito frangos e, assim, a equipe com quatro batedores de caixa carregam em média 2.500 caixas cada um com o peso de 20 a 24 quilos. É óbvio que os números apresentados não são exatos, mas dimensionam o volume de movimentos que a atividade exige dos trabalhadores. A principal queixa dos trabalhadores está relacionada as dores lombares e na coluna - o início do adoecimento. A "saga da avicultura" mutila os trabalhadores de toda a cadeia avícola.
} 
trabalhar nos frigoríficos da região, pois é possível receber um salário um pouco melhor. De acordo com Roberto:

Quando comecei era meio difícil, mas depois fui me acostumando, se acostuma. Depois de um tempo o cara se acostuma bastante. [...] Tipo, o mais difícil era pegar frango. Agora bater caixa é mais bom. Só que é ruim também. Tem que, que nem agora tá chovendo, tem que tá lá em cima do caminhão debaixo de chuva. Temporal, estes dias tava caindo pedrinha e tava lá em cima do caminhão batendo caixa. E lá dentro do aviário é bom, não molha nada. Só que é ruim, que tem aviário que é uma nojeira dentro viu, puro aqueles banhados assim, tipo, molha daí aquela merda do frango fica tudo mole, trabalha naquilo, lá é um cheirão do caralho. ${ }^{30}$

Ao que parece, Roberto não "se acostuma" ao trabalho, pois ele e demais trabalhadores da apanha do frango saíram e entraram diversas vezes da empresa terceirizada - a rotatividade constitui-se como característica da organização do trabalho na cadeia produtiva de aves. ${ }^{31} \mathrm{O}$ mercado de trabalho não é favorável para aqueles que raramente terminam o ensino fundamental, cuja experiência de trabalho é apenas o trabalho braçal, restando poucas as alternativas de emprego na região.

A problematização do processo histórico de integração de avicultores, ironicamente adjetivado como "parceria", às diversas agroindustriais evidenciou-se num sistema de integração perverso, uma vez que levou muitos pequenos proprietários ao endividamento para a instalação dos aviários, manutenção e a pressão para atualização tecnológica contínua. ${ }^{32}$ É o caso de Loreci Dias do Prado Gomes, avicultora há sete anos da Colônia Barretos, em Cascavel, quando entrevistada. A avicultora afirma que se sente desestimulada com a atividade. Loreci trabalha sozinha em um aviário com 13,7 mil aves, pois diante dos prejuízos com a avicultura e das necessidades para a subsistência da família, o marido sentiu-se pressionado a buscar trabalho fora da pequena

\footnotetext{
${ }^{30}$ MARTINS, Roberto de Lima. Entrevista realizada pelo autor e (referência ocultada) em 8 out. 2011. Duração: 35 min.

${ }^{31} \mathrm{Cf}$. VARUSSA, 2013.

${ }^{32} \mathrm{O}$ tema da integração foi tratado demasiadamente como objeto por inúmeros pesquisadores. Para Paulilo, o sistema de integração, "[...] tecnicamente, esse sistema é definido como uma forma de articulação vertical entre empresas agroindustriais e pequenos produtores agrícolas, em que o processo de produção é organizado industrialmente, ou o mais próximo possível desse modelo, com aplicação maciça de tecnologia e capital. São produtores integrados aqueles que, recebendo insumos e orientação técnica de uma empresa agroindustrial, produzem matéria-prima exclusivamente para ela." PAULILO, M. I. S. Produtor e agroindústria: consensos e dissensos. Editora da UFSC: Florianópolis, 1990. p. 19. Além de Paulilo, Cf. BELUSSO, D. "A formação das cooperativas agrícolas e a expansão da avicultura de abate no Oeste paranaense (1970-2010)". In: BOSI, A. (org.) Trabalho e trabalhadores no processo de industrialização recente no Oeste do Paraná (1970-2010): estudos sobre a cadeia avícola. Jundiaí: Paco Editorial, 2014. SILVA, R. N. B., op. cit.. TOEBE ZEN, op. cit.
} 
propriedade: "No começo falaram que ia dar, mas a gente foi vendo que o lucro não dava nem para pagar a prestação do barracão, água, luz e mercado, ele teve que ajudar trabalhando fora". ${ }^{33}$

Nem todas as histórias são parecidas com as narradas pelas irmãs Enge, Pedro Timbola e Leomar Casarolli. A produção avícola é uma atividade economicamente lucrativa apenas para os que possuem três ou mais aviários, com capacidade média acima de vinte mil aves. ${ }^{34}$

O aviário da Loreci é pequeno e não está mais "adequado" às normas exigidas pelas empresas integradoras. Num primeiro momento, até as duas últimas décadas do século XX, a produção industrial de frangos permitiu um incremento na renda da terra extraída pelos pequenos proprietários rurais avicultores, porém, a reorganização da produção da indústria alimentícia e da cadeia produtiva avícola, a partir daquele período, pressionou a ampliação da escala de produção e do "acompanhamento" das "melhorias" do "padrão tecnológico" para a obtenção de uma renda da terra necessária e suficiente para a sobrevivência familiar no campo. Se a pequena propriedade é minúscula - minifúndio - e abriga apenas um aviário e a família não desenvolve outras atividades produtivas simultâneas, como a produção do leite, criação de suínos, de forma integrada ou não a uma agroindústria, e também uma área para plantio, amplamente tecnificados, dificilmente conseguirá sobreviver no campo. Os imperativos do capitalismo ${ }^{35}$ impuseram essa lógica que inviabiliza economicamente as pequenas propriedades não moldadas pelo agronegócio. ${ }^{36}$

As atividades agropecuárias estão hegemonizadas pela organização produtiva amplamente fundamentada em tecnologias, que não são neutras

\footnotetext{
${ }^{33}$ GAZETA DO PARANÁ. Avicultores paranaenses reclamam de preços recebidos. 3 maio 2010. Disponível em: https://www.noticiasagricolas.com.br/noticias/granjeiros/66583-avicultores-paranaenses-reclamam-de-precos-recebidos.html. Acesso em: 15 out. 2011.

${ }^{34}$ No município Munhoz de Mello, região Noroeste do Paraná, o avicultor Francisco Carlos Munhoz Arroyo afirma que a avicultura é uma atividade lucrativa, mas a "granja tem que ser top. Enquanto alguns podem faturar bem, por ano, em um hectare, os que não forem criteriosos talvez não consigam nem pagar o financiamento". O avicultor é proprietário de dois aviários com capacidade de 33 mil frangos em cada galpão e utiliza mão de obra contratada para o trabalho. O DIÁRIO. Engorda de frangos é a atividade mais rentável para o agricultor. Terça-feira, 29 jul. 2014. Disponível em: http://www.aviculturaindustrial.com. br/noticia/engorda-de-frangos-e-a-atividade-mais-rentavel-para-o-agricultor/20140729085808_R_839. Acesso em: 29 jul. 2014.

${ }^{35} \mathrm{Cf}$. WOOD, E. M. A origem do capitalismo. Rio de Janeiro: Jorge Zahar Editor, 2001. WOOD, E. M. 0 império do capital. São Paulo: Boitempo, 2014.

${ }^{36} \mathrm{Na}$ região Oeste do Paraná existem experiências de produção agroecológica e agroflorestal em pequenas propriedades e assentamentos de sem-terra, mas ainda se constitui como minoritária e não representativa da produção agropecuária. Cf. MOREIRA, V. J. A identidade sem-terra e a reforma agrária no Oeste do Paraná: história, memória e metodologia da história oral (décadas de 2000 e 2010). Marechal Cândido Rondon, Unioeste, 2020. Mimeografado.
} 
cientificamente, pois tem uma racionalidade articulada politicamente pelo agronegócio, que constitui na política da burguesia agroindustrial para o campo. ${ }^{37}$

\section{Sobre os pequenos proprietários no Oeste do Paraná}

A pesquisa histórica sobre a reorganização das relações de trabalho no campo deslocou teoricamente o modo de compreensão sobre os pequenos proprietários rurais do Oeste do Paraná, interpretados como camponeses por parte da produção acadêmica e militante. O deslocamento historiográfico afastou-se de tipificações e classificações do pequeno proprietário para construir uma interpretação histórica situada no vivido pelos avicultores no Oeste do Paraná, desde o final da década de $1970 .{ }^{38}$

Para parte da produção acadêmica e militante, a moradia e o trabalho no campo de trabalhadores rurais não proprietários e de pequenos proprietários foram suficientes para o uso do conceito "camponês" ou "campesinato" para a descrição e qualificação desses sujeitos. Ou, de um modo específico, interpretam que a integração às agroindústrias - ao mercado - ocorreu apenas para permitir a reprodução social da unidade familiar camponesa. A mesma literatura corrobora a existência enquanto "classe" dos camponeses no Brasil. Contudo, a problematização não está limitada a possibilidade de se afirmar ou não a presença de modos de vida "camponeses" aos seres humanos (pequenos proprietários e trabalhadores rurais) que habitam naquele ambiente, tradicionalmente, denominado na academia como "campo". ${ }^{39}$

\footnotetext{
${ }^{37} \mathrm{~A}$ história do casal João Pedro e Delci é representativa da tendência experimentada no campo no Oeste do Paraná. 0 casal possui uma pequena propriedade de 2,3 hectares no município de Pato Bragado. E produzem em média 450 litros de leite por dia, com um plantel de cerca de 30 vacas leiteiras. Ainda comercializam o esterco produzido pelo gado, ovos e galinhas caipiras, o que permite custear parte significativa dos gastos com a energia elétrica e a alimentação. A produtividade auferida pelo casal é celebrada pela imprensa como exemplo de gestão e de organização da produção agropecuária, demonstrando a viabilidade da pequena propriedade, pois o casal utiliza-se de animais "melhorados geneticamente" e técnicas de manejo para alcançar a produtividade que permite ao casal obter uma renda mensal elevada, longe do padrão pago aos assalariados rurais. O casal comercializa a produção com a Frimesa Cooperativa Central, que impõe normas técnicas de manejo relacionadas à ordenha e a higiene na produção de leite para determinar o valor remunerado pago ao produtor. CUNICO, J. M. op. cit., p. 51-55.

${ }^{38} \mathrm{~A}$ tipificação comumente está fundamentada nas obras clássicas sobre a questão agrária de Alexander Chayanov, sobre a lógica não capitalista da produção familiar camponesa, Karl Kautsky, sobre a perspectiva reificada da subordinação da agricultura pela indústria, e Vladimir Lênin, com a densa investigação sobre o capitalismo na Rússia, com a diferenciação e desintegração do campesinato. Cf. CHAYANOV, A. V. La organización de la unidad económica campesina. Buenos Aires: Ediciones Nueva Visión, 1974. KAUTSKY, K. A questão agrária. São Paulo: Nova Cultural, 1980. LÊNIN, V. I. O desenvolvimento do capitalismo na Rússia: o processo de formação do mercado interno para a grande indústria. 2 ed. São Paulo: Nova Cultural, 1985. ${ }^{39} \mathrm{O}$ debate no Brasil articula o diálogo com as obras clássicas para avaliar o campo brasileiro, com a
} 
No Oeste do Paraná, quando o pequeno proprietário se integra como avicultor a uma agroindústria, na maioria das vezes, não limita sua atividade produtiva ao aviário. E dedica-se a produção de outras mercadorias agropecuárias com o objetivo de diversificar a produção. Com a gestão da pequena propriedade hegemonizada pelo agronegócio ${ }^{40}$ utilizam permanente, sazonal ou temporariamente a mão de obra assalariada, diante da insuficiência da mão de obra familiar, comumente motivado pela saída dos filhos do campo para o estudo ou para o exercício de outras atividades na cidade..$^{41} \mathrm{O}$ cálculo empresarial e a produção vinculada ao mercado moldaram a reorganização das relações sociais de produção no campo. 0 que as evidências perscrutadas demonstraram foi a produção agropecuária no Oeste do Paraná diversificada e direcionada ao mercado e pequenos proprietários articulados ao agronegócio, como que afirma o senhor Luiz Ari Bernatt:

Noventa por cento, até mais. Olha tem só uns dois ou três que a gente sabe que são só agricultor, o restante tudo tem, é, lavoura, a maioria tem lavoura, independente disso, alguns tem leite, outros tem suíno também. Então, a diversificação muito grande, a diversificação é grande. Então, o produtor não depende só de uma renda, eu acho que a avicultura aqui é uma atividade complementar. ${ }^{42}$

Os pequenos proprietários agropecuaristas assumiram sua condição de proprietários da terra e defendem uma posição cultural e política que os aproximam da burguesia agroindustrial, não divergem do agronegócio e da agroindústria enquanto realidade, pois estão inseridos nas diversas cadeias produtivas (não apenas na avicultura) e dela não querem se excluir (não incluo

discussão sobre a generalização ou não das relações capitalistas na produção agropecuária, ou sobre a expansão do capitalismo criando e recriando relações não capitalistas no campo, entre outros, Cf. BEN, M. Os "nós" da territorialização da Cooperativa Agroindustrial Lar no Oeste paranaense. 2011. 125 f. Dissertação (Mestrado em Geografia) - Programa de Pós-Graduação Mestrado em Geografia, Universidade Estadual do Oeste do Paraná, Francisco Beltrão, 2011. MARTINS, J. S. O cativeiro da terra. 9 ed. 1. reimp. São Paulo: Contexto, 2013. SHANIN, T. A definição de camponês: conceituações e desconceituações - o velho e o novo em uma discussão marxista. NERA, Ano 8, n. 7, p. 10-21, jul./dez. 2005. MOTTA, M.; ZARTH, P. (Orgs.). Formas de resistência camponesa: visibilidade e diversidade de conflitos ao longo da história. v. II. Concepções de justiça e resistência nas repúblicas do passado (1930-1960). São Paulo: UNESP; Brasília, DF: Ministério do Desenvolvimento Agrário, NEAD, 2009. SILVA, R. N. B., op. cit. WELCH, C. A. et al. (Orgs.). Camponeses brasileiros: leituras e interpretações. São Paulo: Editora UNESP; Brasília, DF: Núcleo de Estudos Agrários e Desenvolvimento Rural, 2009.

${ }^{40}$ As cooperativas agroindustriais e as demais agroindústrias da região oferecem regularmente cursos e dias de campo para "formação" e "qualificação" dos integrados e suas famílias.

${ }^{41}$ Como também as diversas evidências de proprietários rurais que exercem outras atividades na cidade e dali administram suas propriedades. Essas propriedades foram oriundas de herança ou como aquisição de um bem como investimento e negócio, principalmente com a engorda de frangos ou de suínos.

${ }^{42}$ BERNARTT, Luiz Ari. Entrevista realizada pelo autor em 24 fev. 2014. Duração: 60 min. 
na problematização o médio e grande proprietário, que, tradicionalmente, assumem a posição de classe em defesa do capitalismo e do agronegócio para moldar a agropecuária). ${ }^{43}$ Não raro, os pequenos proprietários identificam os problemas relacionados ao lugar subalterno e desigual que ocupam nessas cadeias produtivas. ${ }^{44}$

A reorganização da produção avícola contemporânea, controlado por grandes indústrias frigoríficas, privilegia a integração de médios e grandes produtores orientados pela disputa do mercado (um pequeno proprietário consegue organizar a produção agropecuária em larga escala tornando-se médio ou grande produtor), ${ }^{45}$ pois a avicultura industrial tornou-se economicamente viável apenas com a produção em larga escala e a intensa exploração da mão de obra dos trabalhadores vinculados na cadeia avícola.

A lógica do processo de integração adotado pelas agroindústrias de aves constituiu-se em um sistema global. As dinâmicas adotadas para a organização

\footnotetext{
${ }^{43}$ José de Souza Martins há muito tempo apregoou corretamente que a pequena propriedade não era uma contradição para o capitalismo agroindustrial, uma vez que é possível extrair a renda da terra - capitalista - sem apropriar-se da terra. Naquele momento, Martins equivocou-se ao afirmar que a "expansão das relações capitalistas" não ocorre em todos os setores da produção agropecuária, por exemplo, na produção de alimentos. É provável que a avaliação do sociólogo desconsiderasse os sistemas de integração na criação de cadeias produtivas vinculadas produção industrial de alimentos, que em 1981 não era hegemônica no campo. Outra questão não explorada por Martins foi desconsiderar que parte da renda capitalista da terra também é apropriada pelo pequeno proprietário, que reinvesti na propriedade na forma de construção de aviários, granjas para suínos, ordenhas, maquinário para a produção agrícola, entre outros, além da remuneração familiar. MARTINS, J. S. Os camponeses e a política no Brasil: as lutas sociais no campo e seu lugar no processo político. 5a . ed. Petrópolis: Vozes, 1995. p. 173-175. A primeira edição é de 1981. O "capital” na obra de Martins assumiu a condição de sujeito a-histórico, independentemente das vontades e decisões humanas.

${ }^{44}$ Para diversas manifestações e protestos de avicultores no Paraná, Cf. AVICULTORES trabalham no vermelho, apontam dados do Sistema FAEP/SENAR-PR. 20 ago. 2019. Disponível em: https://sistemafaep. org.br/avicultores-trabalham-no-vermelho-apontam-dados-do-sistema-faep-senar-pr/. Acesso em: 28 ago. 2020. AVICULTORES paranaenses reivindicam melhores preços. 4 de maio de 2020. Disponível em: https://www.aviculturaindustrial.com.br/imprensa/avicultores-paranaenses-reivindicam-melhores-precos/20200504-100757-0713. Acesso em: 28 ago. 2020. FOLHA RURAL. Avicultores integrados reclamam de remuneração. Folha de Londrina. versão online, Londrina, 16 de agosto de 2016. Disponível em: https:// www.folhadelondrina.com.br/folha-rural/avicultores-integrados-reclamam-de-remuneracao-955031. html. Acesso em: 28 ago. 2020.

${ }^{45} \mathrm{O}$ senhor Luiz Ari Bernadt afirmou em sua entrevista que a BR Foods de Toledo está "incentivando" a construção de "modais" com aviários com capacidade para mais de 30 mil frangos alojados nos galpões. Cada "modal" compreende a construções de quatro aviários, pelo menos. A tendência é visível em algumas cooperativas agroindustriais no Oeste do Paraná e empresas, como a BR Foods, que modulam o ritmo da reorganização da produção avícola no Brasil, desde o início da avicultura industrial pela Sadia, nas décadas de 1950-60. A BR Foods em Dourados, Mato Grosso do Sul, impôs como condição para manter os contratos de integração a "modernização" dos aviários com a construção de galpões Dark House. CAPITAL NEWS. Dourados, no MS, encabeça estudo sobre a crise na produção de frango. 4 abril de 2014. Disponível em: http://www.aviculturaindustrial.com.br/noticia/dourados-no-ms-encabeca-estudo-sobre-a-crise-na-producao-de-frango/20140404092838_F_781. Acesso em 4 abr. 2014.
} 
da cadeia produtiva de aves nos Estados Unidos e na Europa foram continuamente incorporadas pelas empresas integradoras com os avicultores integrados no Brasil. ${ }^{46} \mathrm{~A}$ indústria de alimentos transformou-se de tal modo nas últimas décadas e são hoje grandes corporações instaladas em diversos países, como ocorre com a estadunidense Tyson Foods, as empresas brasileiras BR Foods e JBS Friboi, que são multinacionais.

As agroindústrias estão política e economicamente articuladas com o agronegócio ${ }^{47}$ - na verdade, não é possível separar os diversos setores que compõe o agronegócio: a relação orgânica entre as indústrias alimentícias, ração, "melhoramento genético", veterinária, entre outras, organizaram-se e criaram entidades, tais como a Associação Brasileira de Proteína Animal (ABPA) e a Associação Brasileira do Agronegócio (ABAG). O agronegócio impôs padrão as atividades agropecuárias e para a gestão empresarial - vive-se no campo a hegemonia do agronegócio. Os imperativos do capital, debatido por Ellen M. Wood, parecem informar à lógica que organizou avicultura industrial no Brasil.48

No final do século XX e início de século XXI, avançou significativamente o projeto de concentração do capital a partir de empreendimentos capitalistas sob a alcunha de "cooperativas" em todo o Paraná e corroboraram a formação das cadeias produtivas agropecuárias e a intensificação dos sistemas de integração entre as agroindústrias e os agropecuaristas. As cooperativas criadas na região Oeste durante as décadas de 1960 e 1970 constituíam-se em empreendimentos que visavam à recepção e o comércio dos produtos agropecuários..$^{49} \mathrm{~A}$ reorganização empresarial das cooperativas a partir da década de 1980 as direcionaram para a instalação de unidades industriais de processamentos da produção agropecuária. ${ }^{50} \mathrm{~A}$ justificativa ideológica esta-

\footnotetext{
${ }^{46}$ Cf. SILVA, R. N. B., op. cit.; PAULILO, op. cit.

${ }^{47}$ BRUNO, R. Um Brasil ambivalente: agronegócio, ruralismo e relações de poder. Rio de Janeiro: Edur. 2009. MENDONÇA, op. cit.

${ }^{48} \mathrm{Cf}$. WOOD, 2014.

${ }^{49}$ De acordo com Ivan Ribeiro, Paulo Cezar e Roberto Besnosik, "No caso do município de Toledo, bem como para o Oeste paranaense de maneira geral, o desenvolvimento das cooperativas na década de [19]70 foi fundamental para viabilizar a modernização (sic) da agricultura na escala e com a rapidez em que esta se verificou. [...] Formava-se uma cadeia de estímulos à modernização (sic) em que a cooperativa tomava parte ativa: os produtores que se modernizavam (sic) sob o efeito combinado de preços remuneradores, crédito farto e assistência técnica impulsionavam a cooperativa, que ampliava continuamente seu quadro de associados, sua capacidade armazenadora (também se utilizando de crédito em condições vantajosas) e as atividades de compra e venda de produtos e repasse de crédito; quem mais se beneficiava, contudo, talvez fosse mesmo o setor produtor de máquinas e insumos modernos, que via seu mercado se multiplicar a cada ano com poder de compra garantido pelo crédito sem limites." RIBEIRO; CESAR; BESNOSIK, op. cit. p. 99-100. ${ }^{50} \mathrm{BELUSSO}, \mathrm{D}$. A integração de agricultores às cooperativas agrícolas abatedoras de frangos no Oeste do Paraná. 2010.
} 
va fundamentada na "agregação" de valor ao produtor agropecuário para a viabilidade econômica das atividades agropecuárias e a manutenção do pequeno proprietário no campo. Contudo, a gestão empresarial das cooperativas agroindustriais não difere das empresas como a BR Foods, que visa o lucro e a acumulação de capital nas relações de integração e na constituição do patrimônio da empresa-cooperativa. A prática do cooperativismo, que no século XIX tradicionalmente se constituiu como prática de organização dos trabalhadores frente à exploração capitalista, foi apropriada por capitalistas de diversos setores e ramos de atividades, com os benefícios e incentivos legais e fiscais do Estado, para a concentração da propriedade privada e do capital no Brasil. Esse processo histórico tem levado a burguesia, como classe, a disputar e hegemonizar os interesses de pequenos proprietários rurais e da produção familiar, configurando os pequenos proprietários como parte da burguesia agrária e industrial no Oeste do Paraná.

\section{Considerações finais}

A narrativa da "saga da avicultura", ou a versão sobre a "pujança" da produção agropecuária sob a égide do agronegócio, criou mitos que ocultam as contradições e as relações de exploração do trabalho no campo. Por outro lado, parte da produção acadêmica e militante parece idealizar ou também mitificar os pequenos proprietários de terra atribuindo a esses sujeitos uma expectativa que não são compartilhadas socialmente pela maioria dos próprios pequenos proprietários de terra. Em 1981, para Ribeiro, Cesar e Besnosik, as transformações na base técnica da agropecuária repercutiram nas relações sociais no campo:

No extremo oposto, o processo de modernização (sic) deu lugar à consolidação
de um estrato significativo de produtores agrícolas apoiados fundamentalmente
no trabalho familiar, mas, ao mesmo tempo, tecnificados e capitalizados no
sentido de uma integração crescente ao complexo agroindustrial e aos circuitos
de financiamentos da produção. [...] Em virtude de uma conjuntura de mercado
extremamente favorável durante a maior parte dos anos [19]70, consolidou-se e
prosperou uma produção familiar capitalizada, correspondente de certa forma
a uma pequena burguesia rural. ${ }^{51}$

291 f. Tese (Doutorado em Geografia) - Programa de Pós-Graduação em Geografia, Universidade Estadual Paulista "Julio de Mesquita Filho", Presidente Prudente, 2010; SILVA, R. N. B. op. cit.

${ }^{51}$ RIBEIRO; CESAR; BESNOSIK, op. cti., p. 145. A história da reorganização produtiva no campo foi amplamente narrada pela produção acadêmica e militante, associado ao que essa literatura nomeou como "modernização conservadora", "modernização dolorosa", "modernização trágica", entre outros adjetivos ao conceito "modernização". Para a análise do processo de tecnificação e mecanização a partir da década de 1970 como "modernização", entre muitos outros, Cf. GONÇALVES NETO, W. Estado e agricultura no Brasil: 
O relatório da pesquisa produzido pelos autores foi concluído em 1981. Para tratar do processo de intensificação da tecnificação e das relações capitalistas no campo, os autores utilizam-se de inúmeras entrevistas com diversos sujeitos implicados com a agropecuária industrial em Toledo, incluindo a avicultura, e concluíram que, naquele momento, ocorreram transformações nas relações sociais e uma reconfiguração nas classes sociais agrárias. Em 1980, as atividades agropecuárias não eram mais as mesmas das décadas de 1950 e 1960. E o processo histórico interpretado pelos autores naquele momento alterou bruscamente até o presente, ampliando significativamente o uso de tecnologias na produção agropecuária e com uso intensivo de mão de obra assalariada (ou como parceiros). Do mesmo modo, se na década de 1980 determinadas relações sociais de trabalho apresentavam-se como tendências, hoje são realidades vividas no campo. ${ }^{52}$

Nas duas últimas décadas, os proprietários de aviários se organizaram em associações de avicultores para reivindicarem contratos de integração em melhores condições com as fábricas processadoras de carne de frango, como a redução no custo na produção e um melhor preço do produto final. ${ }^{53}$ o "fenômeno histórico, que unifica uma série de acontecimentos díspares e aparentemente desconectados, tanto na matéria-prima da experiência como

política agrícola e modernização econômica brasileira, 1960-1980. São Paulo: HUCITEC, 1997. SILVA, J. G. da. A modernização dolorosa: estrutura agrária, fronteira agrícola e trabalhadores rurais no Brasil. Rio de Janeiro: Zahar Editores, 1982. José de Souza Martins é textual ao afirmar que "a nossa (sic) modernidade e a nossa (sic) entrada no mundo capitalista [...] se apóia a nossa (sic) lentidão histórica e a postergação da ascensão social dos condenados à servidão da espera". MARTINS, J. S. O cativeiro da terra. 9 ed. 1. reimp. São Paulo: Contexto, 2013. p. 10. A literatura convencionou a noção "modernização" para qualificar o processo histórico de formação do capitalismo na segunda metade do século XX no Brasil. A "ideologia da modernização" - ou do "melhoramento agrícola", como indicou Ellen M. Wood -, moldou a narrativa hegemônica do capitalismo, procurando ocultar contradições e desigualdades sociais. WOOD, 2001. p. 88-91. Outros historiadores da tradição marxista da historiografia inglesa também criticaram a noção "modernização", Cf. HOBSBAWM, E, J. História operária e ideologia. In: HOBSBAWM, E, J. Mundos do trabalho: novos estudos sobre história operária. $4^{a}$ ed. Rio de Janeiro: Paz e Terra, 2005. p. 24-26. THOMPSON, E. P. Costumes em comum: estudos sobre a cultura popular tradicional. São Paulo: Companhia das Letras, 1998. p. 27. WILLIAMS, R. 0 campo e a cidade: na história e na literatura. São Paulo: Companhia das Letras, 1990. p. 88-96.

${ }^{52}$ MOREIRA, 2016.

${ }^{53}$ Para acesso ao tema a partir da imprensa, Cf. CARRANO, P. Prisão no próprio trabalho. Avicultores integrados à Sadia protestam contra preço e condições impostos pela transnacional. Brasil de Fato, Edição de 3 jan. 2012. Disponível em: http://www.brasildefato.com.br/node/8532. Acesso em: 7 jan. 2012. Por outro lado, a organização das associações de avicultores não busca romper politicamente com o empresariado agroindustrial, mas melhores contratos de integração, Cf. AVICULTORES buscam melhores condições de trabalho no PR. Jornal Correio do Povo do Paraná. Disponível em: <http://www.aviculturaindustrial.com. $\mathrm{br} /$ noticia/avicultores-buscam-melhores-condicoes-de-trabalho-no-pr/20080605105708_33287> Acesso em: 4 nov. 2013. AVICULTORES de Toledo (PR) se organizam e fundam associação. Disponível em: https:// www.aviculturaindustrial.com.br/imprensa/avicultores-de-toledo-pr-se-organizam-e-fundam-associacao/20071123-143107-2993. Acesso em: 19 fev. 2014. 
na consciência" ${ }^{54}$ de identificação histórica e cultural de classe, tem aproximado avicultores e demais pequenos agropecuaristas da região Oeste do Paraná das demandas políticas e culturais do agronegócio e dos sindicatos patronais - a burguesia agroindustrial. E parte significativa dos pequenos proprietários filiados e dirigentes dos sindicatos de trabalhadores rurais mantém como prática sindical o distanciamento político das demandas dos trabalhadores rurais assalariados, cujo vínculo trabalhista ocorre também com pequenos proprietários. ${ }^{55}$

A defesa da propriedade privada da terra em detrimento da pauta dos sem-terra, quilombolas e movimentos sociais de retomada indígenas de suas terras, por exemplo, têm produzido valores liberais de classe entre os pequenos proprietários, distanciando-se politicamente de uma identidade de interesses comuns e de solidariedade entre pequenos proprietários e os trabalhadores rurais não proprietários e sem terras no Oeste do Paraná. Como afirmou Edward P. Thompson:

Nas sociedades modernas, as relações de produção encontram expressão na
formação e luta (ocasionalmente, no equilíbrio) das classes. Entretanto, classe
não é, como gostariam alguns sociólogos, uma categoria estática: tais e tais
pessoas situadas nesta e naquela relação com os meios de produção, mensuráveis
em termos positivistas ou quantitativos. Classe, na tradição marxista, é (ou
deve ser) uma categoria histórica descritiva de pessoas numa relação no
decurso do tempo e das maneiras pelas quais se tornam conscientes de suas
relações, como se separam, unem, entram em conflito, formam instituições e
transmitem valores de modo classista. Nesse sentido, classe é uma formação
tão "econômica" quanto "cultural"; é impossível favorecer um aspecto em
detrimento do outro, atribuindo-se uma prioridade teórica. ${ }^{56}$

As relações sociais capitalistas fundamentadas na reorganização da produção agropecuária tornaram-se hegemônicas no final do século XX. Esse processo histórico está intimamente associado às disputas dos trabalhadores por direitos trabalhistas e aos diversos movimentos sociais de luta pela terra e reforma agrária. ${ }^{57}$ A reorganização do trabalho no campo pelos

\footnotetext{
${ }^{54}$ THOMPSON, E. P. A formação da classe operária inglesa. A árvore da liberdade, v. 1. 3 ed. Rio de Janeiro: Paz e Terra, 1997. p. 9.

${ }^{55}$ Cf. CHRIST, F. M. Memórias, projetos e lutas na formação história do Sindicato dos Trabalhadores Rurais de São Miguel do Iguaçu/PR (1970-2009). 2010. 157 f. Dissertação (Mestrado em História) - Programa de Pós-Graduação Stricto Sensu em História, Universidade Estadual do Oeste do Paraná, Marechal Cândido Rondon, 2010. VARUSSA, R. J. Disputas na Justiça do Trabalho: memórias e histórias a partir do Oeste do Paraná (década de 1980 a 2000). Diálogos, DHI/PPH/UEM, v. 13, n. 2, p. 441-460, 2009. MOREIRA, 2016.

${ }^{56}$ THOMPSON, 2001, p. 260.

${ }^{57}$ Cf. MORAES JUNIOR, L. R. Mastro: a formação do Movimento dos Agricultores Sem Terra do Oeste do Paraná
} 
proprietários de terra relaciona-se ao movimento hegemônico de negação de direitos trabalhistas previstos pelo Estatuto do Trabalhador Rural, de 1963, e, posteriormente, consagrados na Constituição de 1988, que pressionaram, contraditoriamente, a intensificação do uso de tecnologias, tais como, mecanização da produção, sementes transgênicas, utilização de diversos implementos agrícolas, venenos (inseticidas, herbicidas, fungicidas), entre outros. Assim, as transformações na base técnica da agropecuária não estiveram apenas relacionadas ao aumento da produtividade. Em substituição das relações sociais de trabalho anteriormente encontradas no campo (posseiro, arrendatário, parceiro, agregado, trabalhador assalariado permanente, entre outros), que possibilitava ao trabalhador e sua família residirem no campo e usufruir de moradia, cultivo de subsistência, criação de pequenos animais, lenha, entre outros, assentada em direitos costumeiros, ocorreu à expulsão e a expropriação dos trabalhadores rurais do campo. Em seu lugar foram introduzidas relações de trabalho baseadas em diversas formas de assalariamento, não raro, sem registro em carteira de trabalho e garantias previdenciárias. O trabalho nos aviários, nas granjas de suínos e na produção de leite não são mais nas mesmas condições tal como aconteceu o trabalho na agropecuária há cinco ou seis décadas.

Artigo recebido para publicação em 13/11/2019

Artigo aprovado para publicação em 03/09/2020

(1970-1990). 2011. 151 f. Dissertação (Mestrado em História) - Programa de Pós-Graduação Stricto Sensu em História, Universidade Estadual do Oeste do Paraná, Marechal Cândido Rondon, 2011. MOREIRA, V. J. História oral e reforma agrária: a experiência social de trabalhadores rurais sem-terra em Sumaré, interior de São Paulo (décadas de 1980 e 1990). São Paulo: Edições Verona, 2019. MOREIRA, 2020. 